\title{
Advanced mechanical and thermal characterization of 3D Bioextruded Poly(-caprolactone)-based composites
}

DOI:

10.1108/RPJ-10-2016-0165

\section{Document Version}

Accepted author manuscript

Link to publication record in Manchester Research Explorer

\section{Citation for published version (APA):}

Wang, H., Domingos, M., \& Scenini, F. (2018). Advanced mechanical and thermal characterization of 3D

Bioextruded Poly(-caprolactone)-based composites. Rapid Prototyping Journal, 24(4). https://doi.org/10.1108/RPJ10-2016-0165

\section{Published in:}

Rapid Prototyping Journal

\section{Citing this paper}

Please note that where the full-text provided on Manchester Research Explorer is the Author Accepted Manuscript or Proof version this may differ from the final Published version. If citing, it is advised that you check and use the publisher's definitive version.

\section{General rights}

Copyright and moral rights for the publications made accessible in the Research Explorer are retained by the authors and/or other copyright owners and it is a condition of accessing publications that users recognise and abide by the legal requirements associated with these rights.

\section{Takedown policy}

If you believe that this document breaches copyright please refer to the University of Manchester's Takedown Procedures [http://man.ac.uk/04Y6Bo] or contact uml.scholarlycommunications@manchester.ac.uk providing relevant details, so we can investigate your claim.

\section{OPEN ACCESS}




\title{
Advanced mechanical and thermal characterization of 3D Bioextruded Poly( $\varepsilon$-caprolactone)-based composites
}

\author{
H. Wang ${ }^{1}$, M. Domingos ${ }^{2}$, F. Scenini ${ }^{*}$
}

1School of Materials, the University of Manchester, Manchester, United Kingdom

2School of Mechanical, Aerospace and Civil Engineering, the University of Manchester, Manchester, United Kingdom

*Corresponding author: Fabio.Scenini@manchester.ac.uk, tel: +44-0161 306 2933;

E-mail: hanxiao.wang@manchester.ac.uk, marco.domingos@manchester.ac.uk, Fabio.Scenini@manchester.ac.uk

\begin{abstract}
Purpose - The main purpose of the present work is to study the effect of nano hydroxyapatite (HA) and graphene oxide $(\mathrm{GO})$ particles on thermal and mechanical performances of 3D printed poly $(\varepsilon-$ caprolactone) (PCL) filaments used in Bone Tissue Engineering (BTE).

Design/methodology/approach - Raw materials were prepared by melt blending, followed by 3D printing via 3D Discovery (regenHU Ltd., $\mathrm{CH}$ ) with all fabricating parameters kept constant. Filaments, including pure PCL, PCL/HA, and PCL/GO, were tested under the same conditions. Several techniques were used to mechanically, thermally, and microstructurally evaluate properties of these filaments, including Differential Scanning Calorimetry (DSC), tensile test, nano indentation, and Scanning Electron Microscope (SEM).

Findings - Results show that both HA and GO nano particles are capable of improving mechanical performance of PCL. Enhanced mechanical properties of PCL/HA result from reinforcing effect of HA, while a different mechanism is observed in PCL/GO, where degree of crystallinity plays an important role. In addition, GO is more efficient at enhancing mechanical performance of PCL compared with HA.

Originality/value - For the first time, a systematic study about effects of nano HA and GO particles on bioactive scaffolds produced by Additive Manufacturing (AM) for bone tissue engineering applications is conducted in this work. Mechanical and thermal behaviors of each sample, pure PCL, PCL/HA and PCL/GO, are reported, correlated, and compared with literature.
\end{abstract}

Keywords: Additive Manufacturing, Polycaprolactone, Graphene Oxide, Hydroxyapatite, Mechanical characterization, Tissue Engineering.

Paper type: Research paper 


\section{Introduction}

The loss or failure of a tissue is one of the most frequently encountered problems in human health care. For example, around 3.5 million people suffered from bone fractures in 2010 in the European Union (EU) (Hernlund et al., 2013) and a good portion of them were repaired via the use of metallic implants (e.g. plates). However, one of the most limiting factors in current clinical treatments for bone fracture is associated with the mechanical properties mismatch between human bones and metallic plates which can lead to stress-shielding effects in internal and external fixation (Amini et al., 2012).

Although most tissues are able to self-heal and regenerate after damage, this process is slow and limited to some extent. Recent advances in the field of bone tissue engineering (BTE) suggest the possibility of using highly porous scaffolds seeded with donor cells that enables the support and the growth of fragmented bones until complete regeneration (Amini et al., 2012).

An ideal scaffold should be biocompatible and bioactive, allowing cells to adhere and migrate onto it. Meanwhile, biodegradability is also important and degradation should occur at a similar rate to the formation of new tissues (Domingos et al., 2013a; Domingos et al., 2013b; Caetano et al., 2016). The scaffolds also need to have mechanical properties consistent with human bones and providing mechanical integrity to function from the moment of implantation. In addition, architecture of an ideal scaffold should be highly porous with interconnected pores for cellular penetration and diffusion of nutrients as well as waste products (O’Brien, 2011).

The introduction of additive manufacturing (AM) in the field of tissue engineering has enabled the manufacturing of scaffolds with customized external shape and predefined internal porosity as well as interconnectivity (Arafat et al., 2014). Compared with conventional fabrication methods, for instance gas foaming and phase separation, AM techniques are able to rapidly produce very complex constructs with high accuracy and resolution. Additionally, along with the ability to use multiple raw materials that leads to locally graded composition, good control over size and distribution of pores, and high product reproducibility, they make AM the most promising technique to produce bioactive scaffolds in BTE field (Domingos et al., 2009a).

Clearly, the fabrication techniques employed have a strong influence on the final biomechanical properties of the 3D printed scaffolds. The selection of an appropriate fabrication system depends on the application of the tissue analogue used to produce it but more importantly on the biomaterials used. In the context of tissue engineering, and more specifically in the case of BTE, Poly(E-caprolactone) (PCL) has been widely investigated and holds approval by the Food and Drug Administration (FDA) for medical purposes. The reasons for its broad application rely on the ability to easily tailor its mechanical properties, biocompatibility and biodegradability (Dash and 
Konkimalla, 2012). PCL is a semi-crystalline thermoplastic ( $\sim 50 \%$ of crystallinity) with a relatively low melting temperature $\left(\mathrm{T}_{\mathrm{m}}\right)$ at around $60^{\circ} \mathrm{C}$, which provides easy formability and processability at relatively low cost. The glass transition temperature $\left(\mathrm{T}_{\mathrm{g}}\right)$ of $\mathrm{PCL}$ is around $60^{\circ} \mathrm{C}$, and therefore this material will have flexible and rubber-like behaviour at room as well as body temperature. Mechanical properties of PCL are dependent on many factors, for example, sample conditions (Tan et al., 2005), testing conditions (Nor et al., 2016) and fabrication process (Domingos et al., 2012).

Despite all the above mentioned advantages, PCL still presents some drawbacks that hinder its successful use in BTE, namely the low mechanical properties compared to native bone, lack of bioactivity and slow degradation rate. In order to overcome these issues, several groups have been exploring the ability of PCL to form blends with other materials and produce organic-inorganic composite scaffolds with enhanced bioactivity and mechanical properties (Fu et al., 2012; Lohfeld et al., 2012; Hyung and Seong, 2014).

One of the most used strategies encompasses the incorporation of bioactive nano particles, for example hydroxyapatite (HA) and graphene oxide (GO) into a PCL matrix. The use of HA is intended to mimic the mineral phase of the bone that is composed of around $67 \mathrm{wt} \%$ of calcium phosphates, which provides the required stiffness. HA $\left(\mathrm{Ca}_{10}\left(\mathrm{PO}_{4}\right)_{6}(\mathrm{OH})_{2}\right)$ is a crystalline form of calcium phosphate, so it shows outstanding biocompatibility, bioactivity and osteoconductivity (Suchanek and Yoshimura, 1998; Zhao et al., 2015). Apart from its bio-functionality, other studies have proven that HA is able to improve PCL's mechanical properties (Hao et al., 2002; Baji et al., 2007). Hao et al. reported that inclusion of HA makes PCL/HA stronger and stiffer, but less ductile compared with pure PCL. Thermal properties of PCL are slightly influenced by the presence of HA particles (Hao et al., 2002). Similar effects of HA are also reported in other studies (Baji et al., 2007).

Graphene and its derivatives are attractive filler materials for polymer matrix composites (PMC) as a result of their outstanding electronic, thermal and mechanical properties (Huang et al., 2011). Polymers usually possess poor electrical conductivity, for example conductance of PCL is less than $10^{-15} \mathrm{~S} \cdot \mathrm{cm}^{-1}$. By including graphene or its derivatives such as graphene oxide (GO) into PCL, it is possible to increase the overall conductance, making it capable of modulating the behaviour of neural cells (e.g. neural differentiation) that may require bioelectrical signal transmissions (Lee et al., 2013). In addition, graphene is biocompatible and even beneficial for growing cells, for instance supporting the adhesion and proliferation of mouse fibroblast cells (Wan and Chen, 2011; Sayyar et al., 2013). Due to these unique properties, several researchers have been carrying out studies to investigate the effects of graphene or graphene oxide as a reinforcing agent on mechanical, electrical and bioactive properties of composite materials, including GO reinforced PCL (Kai et al., 
2008; Wan and Chen, 2011; Wang et al., 2013). It is reported inclusion of GO would significantly increase tensile strength and modulus of PCL (Wan and Chen, 2011), which is consistent with results of the research conducted by Wang et al (Kai et al., 2008; Wang et al., 2013). Reinforcing effects of nanoparticles (HA/GO) are generally attributed to the strong interaction between matrix and embedded particles (Hao et al., 2002; Kai et al., 2008; Wan and Chen, 2011; Wang et al., 2013).

Despite many studies on PCL, the mechanism behind enhanced mechanical properties of PCLbased composites is not completely understood. It has been widely agreed that inclusion of nanoparticles (HA/GO) increases the crystallinity of PCL. This phenomenon is attributed to embedded particles, which act as numerous nucleation sites during solidification (Hao et al., 2002; Baji et al., 2007; Kai et al., 2008; Wang et al., 2013). The mechanical behaviour of PCL is also reported to be associated with its degree of crystallinity (Estellés et al., 2008; Zhao et al., 2015). Therefore, PCL/HA as well as PCL/GO, cannot be simply treated as polymer matrix composites (PMCs), and reinforcing effects of these nano particles may result from increased crystallinity. Additionally, the reports present in the literature do not provide a meaningful insight into the effect of the addition of the above mentioned nano particles due to the diverse sample preparation methods. Combined with various fabrication procedures and testing conditions used, all of them could affect mechanical behaviours of the composites.

In this work, nano HA and GO particles are incorporated into PCL separately in order to investigate their effects on mechanical and thermal properties of 3D printed bioactive scaffolds for BTE applications. It is known that mechanical properties of 3D bioextruded PCL scaffolds are sensitive to fabrication parameters, particularly for deposition rate (DR) and screw rotation velocity (SRV) (Domingos et al., 2012). As far as the authors are aware, this is the first time that both PCL/HA and PCL/GO composites are studied systematically, thus offering an opportunity to gain an insight into the mechanism behind reinforcing effects and efficiencies of HA and GO nano particles on PCL. The 3D printed specimens were characterized mechanically (via tensile test and nano indentation), thermally to obtain thermal properties (via differential scanning calorimetry, DSC) and microstructurally (via scanning electron microscopy, SEM).

\section{Materials and methods}

\subsection{Materials}

PCL (CAPA 6500, Mw = 50,000) in the form of pellets was obtained from Perstorp Caprolactones (Cheshire, UK). Synthetic nano HA (particle size $\leq 200 \mathrm{~nm}$ ) was purchased from Sigma-Aldrich (Gillingham, UK), and used without further modifications. Pristine graphene and GO were 
synthetized at the Department of Chemical Engineering, National Taiwan University of Science and Technology, Taipei, and details of the process can be found elsewhere (Wang et al., 2016).

\subsubsection{Preparation of PCL/HA and PCL/GO blends}

The blends used in 3D printing were prepared by melt blending, details of which are described elsewhere (Wang et al., 2016). Raw materials were carefully weighed to ensure weight percentage of HA and GO in PCL/HA and PCL/GO were $20 \%$ and $0.75 \%$, respectively. Contents of both inclusions were selected based on previous experiments conducted in this group to achieve the best combination of biomechanical performance and printability of PCL scaffolds (Domingos et al., 2016).

\subsubsection{D printing of composite filaments}

The 3D printing of composite filaments was performed using the 3D Discovery (regenHU Ltd., $\mathrm{CH}$ ). This is an extrusion-based system equipped with two printing heads (low and high temperature) that enables the layer-by-layer production of $3 \mathrm{D}$ scaffolds. In this work the screw assisted, high temperature printing head was used. Processing parameters were set based on previous works, namely melting temperature $\left(90^{\circ} \mathrm{C}\right)$ and screw rotation velocity (22 $\left.\mathrm{rpm}\right)$ (Domingos et al., 2009a; Domingos et al., 2012; Patricio et al., 2014). In this process, materials are extruded in a molten state through a nozzle with internal diameter of $500 \mu \mathrm{m}$ and solidified almost instantaneously after leaving the printing head. Both phase changes and shear movements are determined by processing conditions, which probably give rise to physical and/or chemical variations in final products. To avoid that variation, all processing parameters were kept constant independently of the material being processed. Principle parameters affecting mechanical properties of 3D bioextruded scaffolds have been reported elsewhere (Domingos et al., 2012).

\subsection{Mechanical characterization}

\subsubsection{Tensile test}

Tensile properties of each sample, including Young's modulus (E), yield stress $\left(\sigma_{\mathrm{y}}\right)$, and yield strain $\left(\varepsilon_{y}\right)$ were measured by Instron 3344 single column testing system (Illinois Tool Works Inc., USA) equipped with a $10 \mathrm{~N}$ load cell according to ASTM C1557-14. Sample diameter was measured with the help of ImageJ (NIH, USA). Gage length and crosshead speed were set to be $25.4 \mathrm{~mm}$ and 5 $\mathrm{mm} / \mathrm{min}$, respectively. In order to avoid stress concentration, a tab that could smoothly transfer load from a pair of mechanical grips towards a single filament was specially designed according to dimensions of the grip. A schematic representation is shown in Figure 1. For each sample, 25 tests were performed in order to obtain statistically reliable results. 


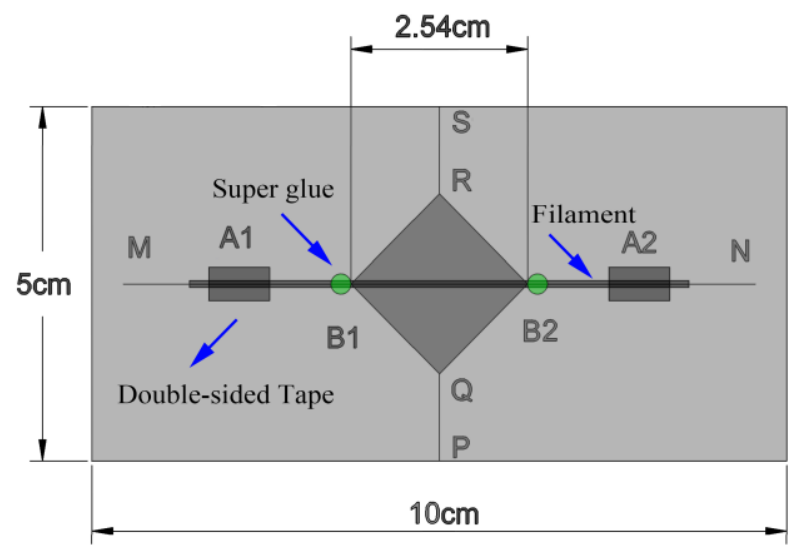

Figure 1 Schematic representation of the specially designed mounting tab, a modification of the one used in ASTM C1557-14. This tab was employed to fix a filament during tensile test in order to transfer load from mechanical grips to one filament smoothly. A piece of double-sided tape was placed at $\mathrm{A} 1$ and $\mathrm{A} 2$ on the tab. Then a filament was aligned according to line $\mathrm{MN}$ and stuck to the tape. A drop of super glue was added at B1 and B2, ensuring the gage length was equivalent to separation between these two points which was $25.4 \mathrm{~mm}$. Finally, the filament was cut somewhere between $\mathrm{A} 1$ and $\mathrm{B} 1$ as well as $\mathrm{A} 2$ and B2, making sure it was only fixed at B1 and B2 with the tab.

\subsubsection{Nano indentation}

A nano indentation G200 system (Agilent Technologies, USA) equipped with a diamond Berkovich indenter was employed in this work to investigate surface properties of these filaments and to obtain Young's modulus ( $\left.\mathrm{E}_{\mathrm{I}}\right)$ and hardness $(\mathrm{H})$ (Oliver and Pharr, 2004) of the specimens. A fine surface for indentation is required due to intrinsic nature of the technique. Samples were prepared by traditional methods used in Metallurgy, the final step of which was diamond polishing to a $0.25 \mu \mathrm{m}$ finish. Key parameters that control load-pause-unload manner of the indenter, for instance maximum penetration depth, allowable drift rate, and peak hold time, were $2000 \mathrm{~nm}, 0.15 \mathrm{~nm} / \mathrm{s}$, and $10 \mathrm{~s}$, respectively. Poisson's ratio of all samples was assumed to be 0.3 (Williams et al., 2005; Eshraghi and Das, 2010). For each sample, a $5 \times 5$ indentation matrix was performed and separation between neighboring indents was $50 \mu \mathrm{m}$.

\subsection{Thermal characterization}

Glass transition temperature $\left(\mathrm{T}_{\mathrm{g}}\right)$, melting temperature $\left(\mathrm{T}_{\mathrm{m}}\right)$, crystallization temperature $\left(\mathrm{T}_{\mathrm{c}}\right)$ and degree of crystallinity $\left(\mathrm{X}_{\mathrm{c}}\right)$ of each sample were measured by a differential scanning calorimetry (DSC) machine DSC Q-100 (TA Instruments, USA) according to ASTM E1356-08 (Reapproved 2014). Samples were cut into 2-3 mm segments and weighed before being sealed into a hermetic Aluminum pan. Each pan contained about 5-7 mg samples. Testing was carried out in heatingcooling-heating $(\mathrm{HCH})$ mode with an empty pan acting as reference. Lower and upper temperatures were $-90^{\circ} \mathrm{C}$ and $100^{\circ} \mathrm{C}$, respectively. Heating and cooling rates were both kept at $10{ }^{\circ} \mathrm{C} / \mathrm{min}$. All 
tests started at room temperature and $\mathrm{N}_{2}$ served as the purge gas with a flow rate of $50 \mathrm{~mL} / \mathrm{min}$. Each sample was tested 3 times for the purpose of reliability and reproducibility. Thermal properties were analyzed by a Universal Analysis 2000 system (TA Instruments, USA).

\subsection{Morphological characterization (SEM)}

A Quanta 200 system (FEI, USA) was employed to characterize microstructures of pure PCL, PCL/HA and PCL/GO filaments. Samples were coated with carbon and observed in high vacuum mode.

\subsection{Statistical analysis}

Statistical tests were carried out within Mathematica (Wolfram, USA) when different samples exhibit similar mean value for a particular property in order to determine their relationship. Statistical differences were set at $\mathrm{p}<0.01$.

\section{Results and discussion}

Experimental results show direct influences of both types of nano particles on mechanical and thermal behaviors of PCL composite filaments.

\subsection{Morphological characterization}

Figure 2 displays a SEM image of an as-fabricated PCL/HA filament where the HA particles appear as white dots. A uniform distribution of these particles was observed which indicates a good mixture of raw materials. After straining the filament, micro cracks were found at the interface of PCL and HA nano particles, as shown in Figure 3. The interface clearly shows signs of void formation which are the initiation sites for the fracture. Details of sample diameters are listed in Table I.

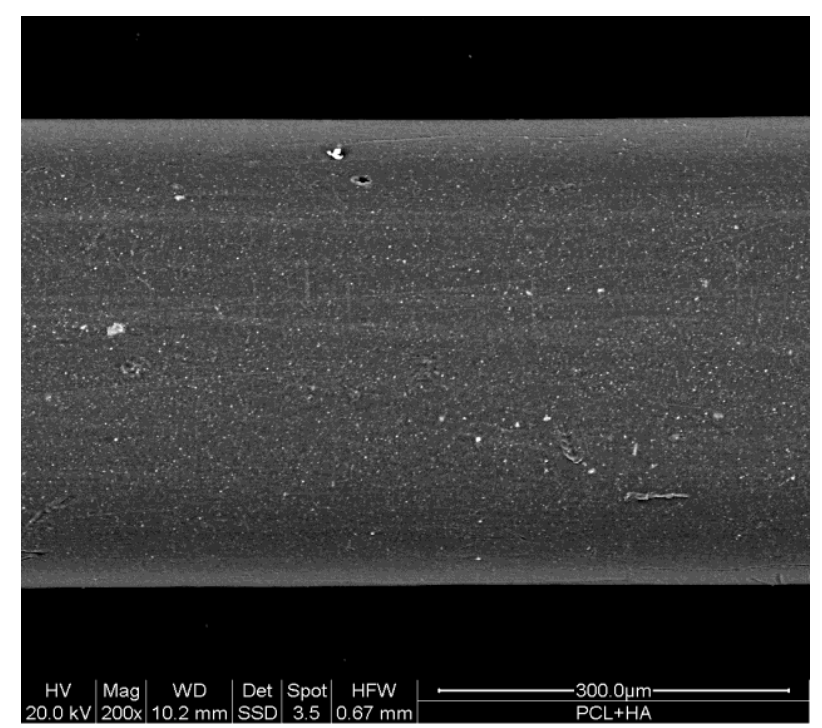

Figure 2 An as-fabricated PCL/HA filament observed under scanning electron microscope. 


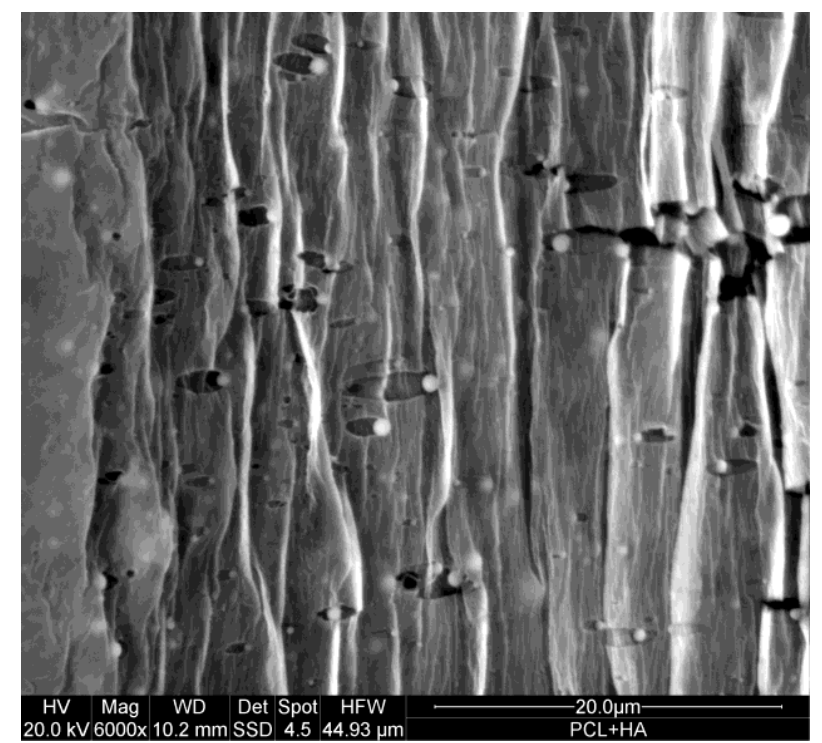

Figure 3 Morphological features after straining a PCL/HA filament. Formation of voids is observed at the interface of matrix/second particles and this is the place where failure initiates.

Table I Diameters of different samples obtained from ImageJ.

\begin{tabular}{cccc}
\hline Sample & Mean $/ \mu \mathrm{m}$ & $\mathrm{STD} / \mu \mathrm{m}$ & $\mathrm{CV} / \%$ \\
\hline pure PCL & 515.2 & 2.3 & 0.4 \\
PCL/HA & 500 & 2.6 & 0.5 \\
PCL/GO & 517.2 & 3.1 & 0.6 \\
\hline
\end{tabular}

\subsection{Mechanical characterization}

\subsubsection{Tensile test}

Figure 4 shows typical engineering stress-strain curves of three different filaments. All samples deformed elastically at the initial stage, suggesting a stiff mechanical response. Young's modulus (E) was calculated by curve-fitting according to equation 1 in Mathematica, where $\sigma$ and $\varepsilon$ represent strain and stress, respectively. Plastic deformation occurred afterwards, where stiffness decreased, followed by necking. Yield strength $\left(\sigma_{\mathrm{y}}\right)$ is defined as the stress when equation 2 is valid, the corresponding strain of which is the yield strain $\left(\varepsilon_{\mathrm{y}}\right)$. Results obtained from tensile tests are plotted in Figure 5. 


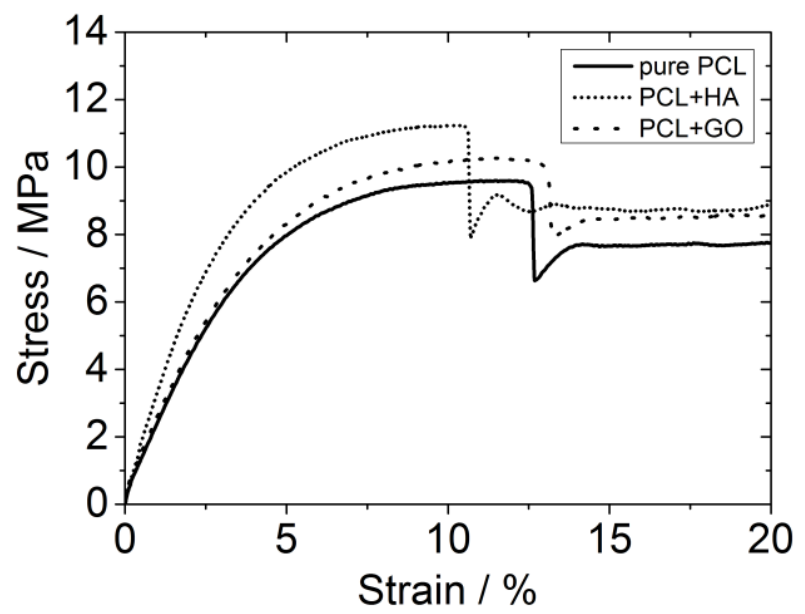

Figure 4 Typical engineering stress-strain curves of three different filaments obtained from tensile tests.

$\sigma=\mathrm{E} \cdot \varepsilon$

$$
\frac{d \sigma}{d \varepsilon}=0
$$

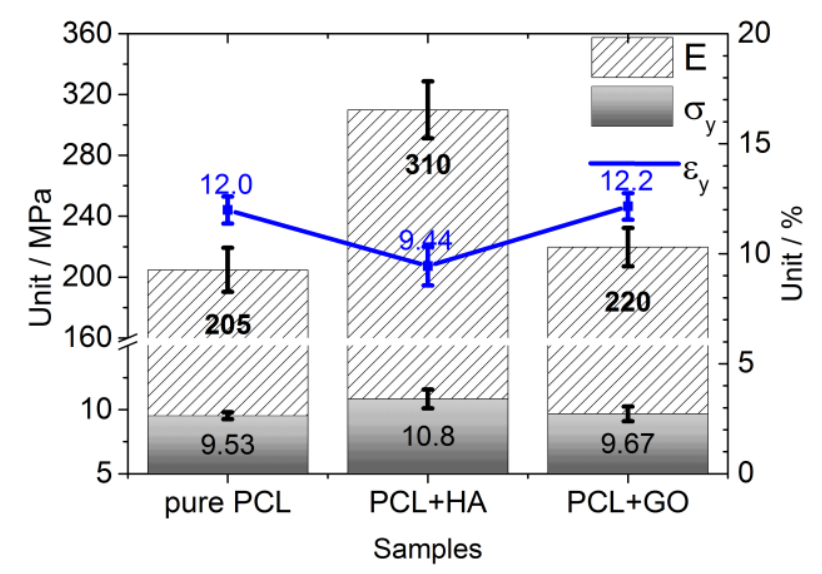

Figure 5 Young's modulus $(E)$, yield strength $\left(\sigma_{y}\right)$ and yield strain $\left(\varepsilon_{y}\right)$ of three different filaments.

Compared with pure PCL, a significant (51\%) increase in Young's modulus was observed by including 20 wt.\% HA. The presence of 0.75 wt.\% GO also increased that of PCL (7\%), but in a more efficient way when considering the ratio of increase in Young's modulus to percentage of nano particles (PCL/HA, 2.6; PCL/GO, 9.3). Additionally, the incorporation of HA increased yield strength but decreased yield strain of pure PCL by $14 \%$ and $22 \%$, respectively. Influence of GO on yield strength and strain is highly limited according to Figure 5. Results of a statistical test showed that pure PCL and PCL/GO had the same mean yield strain. Similar results were also obtained in yield strength. Thus the incorporation of GO does not affect yield strength and strain of PCL. 


\subsubsection{Nano indentation}

Figure 6 shows typical load-depth curves of three different samples. Indentation modulus $\left(\mathrm{E}_{\mathrm{I}}\right)$ and hardness $(\mathrm{H})$ of each sample were analyzed via NanoSuite (Agilent technologies, USA) and the results are displayed in Figure 7.

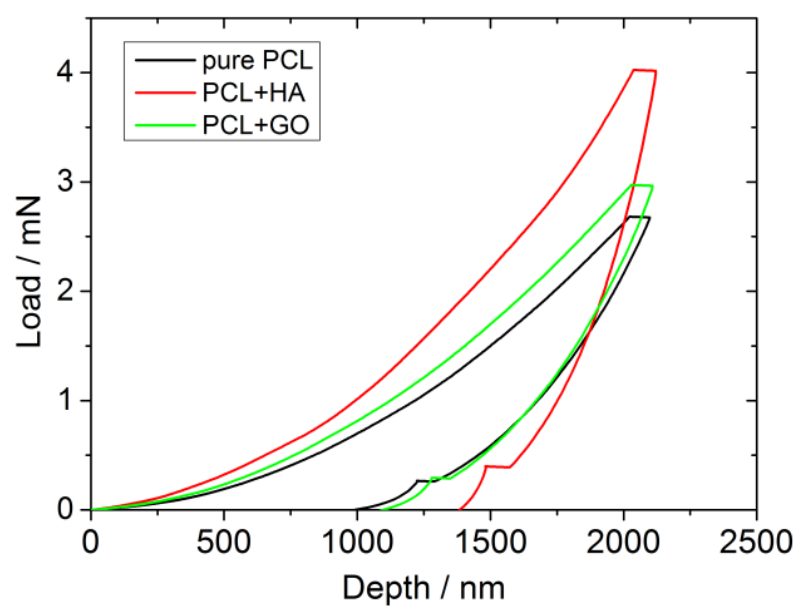

Figure 6 Load-depth curves of three different samples obtained from nano indentation.

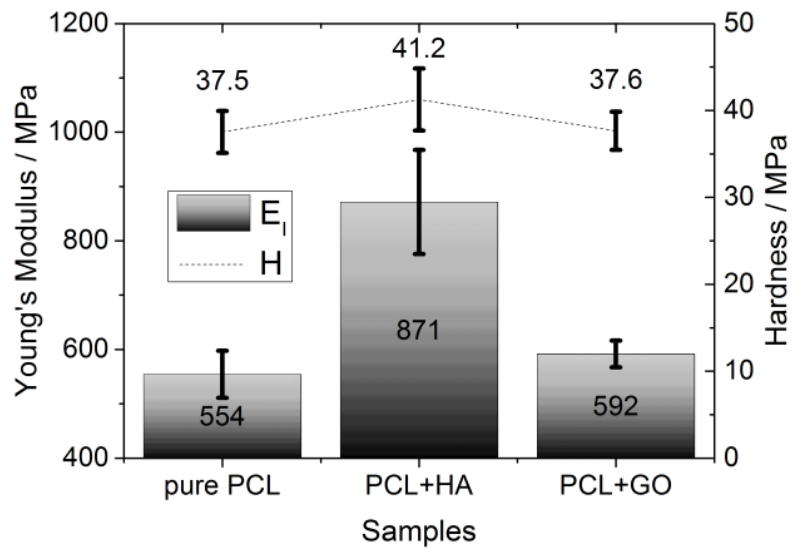

Figure 7 Indentation modulus $\left(\mathrm{E}_{\mathrm{I}}\right)$ and hardness $(\mathrm{H})$ obtained from nano indentation.

The hardness of PCL/HA increased by $10 \%$ in comparison with pure PCL. However, the relationship between hardness of PCL/GO and pure PCL was not distinct, therefore a statistical test was performed and the result suggested that they are statistically the same. By incorporating HA and $\mathrm{GO}$, indentation moduli were found to be $57 \%$ and $7 \%$ higher than that of pure PCL, respectively. Figure 8 is a comparison of results obtained from tensile test and nano indentation. For each sample, indentation modulus $\left(\mathrm{E}_{\mathrm{I}}\right)$ is almost three times as high as Young's modulus (E), resulting from the distinct nature of these two techniques (Salehi et al., 2014). Moduli obtained from different techniques show the same trend, indicating properly designed experiments and reliable results. 


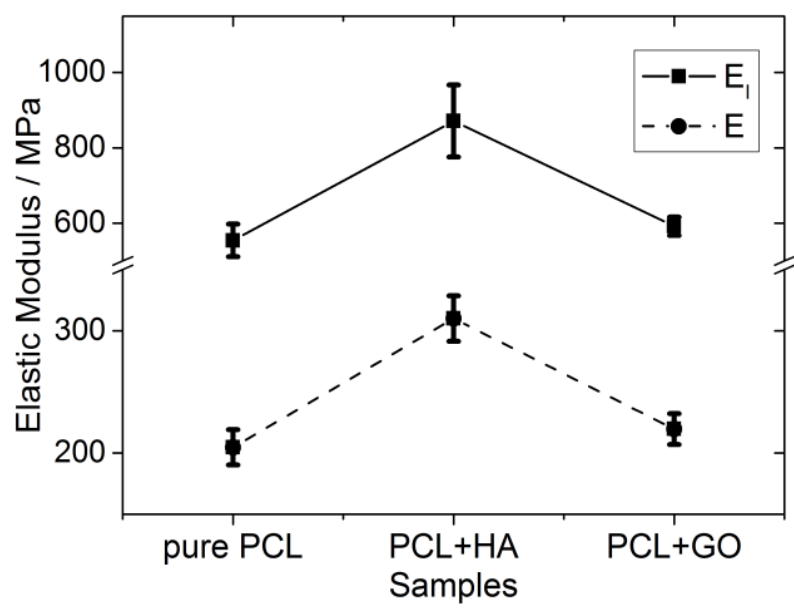

Figure 8 A comparison of Young's modulus obtained from tensile test (E) and nano indentation $\left(\mathrm{E}_{\mathrm{I}}\right)$.

The inclusion of HA nano particles made PCL/HA less ductile, but stronger, harder and significantly stiffer than pure PCL. GO did not have the same effects as HA. Mechanical properties of PCL/GO barely showed differences compared with that of pure PCL except for Young's modulus. This is surprising since it was found even if at an extremely low concentration $(0.75$ wt.\%), GO increased Young's modulus of PCL by 7\%. In addition, efficiency of GO in terms of improving Young's modulus is higher compared to HA.

\subsection{Thermal characterization}

Heat flow-temperature curves of a typical heating-cooling-heating process in a DSC cycle are shown in Figure 9, where the glass transition temperature $\left(\mathrm{T}_{\mathrm{g}}\right)$, melting temperature $\left(\mathrm{T}_{\mathrm{m}}\right)$, crystallization temperature $\left(\mathrm{T}_{\mathrm{c}}\right)$, and degree of crystallinity $\left(\mathrm{X}_{\mathrm{c}}\right)$ were obtained.

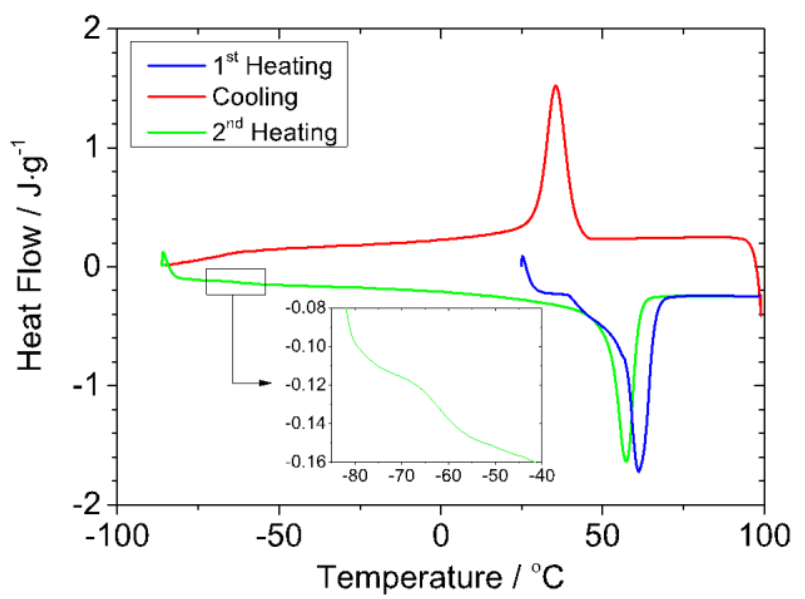

Figure 9 Heat flow-temperature curves of a typical heating-cooling-heating process in a DSC cycle. 
Three types of $\mathrm{T}_{\mathrm{g}}$ were obtained, including onset point, midpoint and end point, as displayed in Figure 10. Inclusion of HA/GO particles showed almost no influence on $\mathrm{T}_{\mathrm{g}}$. Based on the result of a statistical test, significant differences were not identified within each type of $\mathrm{T}_{\mathrm{g}}$. Consequently, the presence of HA/GO nano particles did not affect glass transition temperature of PCL.

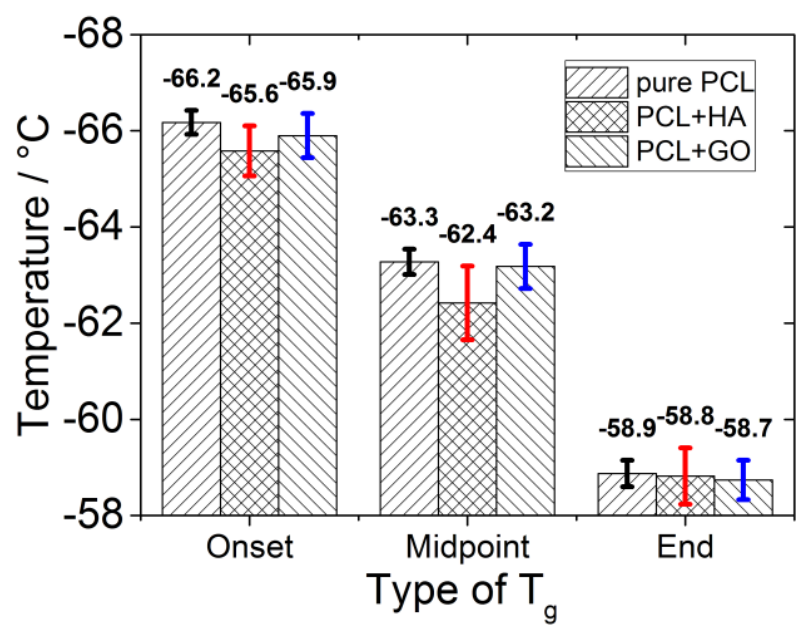

Figure 10 Three types of glass transition temperatures $\left(\mathrm{T}_{\mathrm{g}}\right)$ of different samples.

$\mathrm{T}_{\mathrm{m}}$ and $\mathrm{T}_{\mathrm{c}}$ of each sample are shown in Figure 11. According to the result of a statistical test, the mean $\mathrm{T}_{\mathrm{m}} / \mathrm{T}_{\mathrm{c}}$ of pure PCL and PCL/HA were statistically the same, so the presence of HA had no influence on $\mathrm{T}_{\mathrm{m}} / \mathrm{T}_{\mathrm{c}}$ of PCL. Compared with pure PCL, $\mathrm{T}_{\mathrm{m}}$ and $\mathrm{T}_{\mathrm{c}}$ of PCL/GO increased by $2 \%$ and $5 \%$, respectively. With the presence of $\mathrm{HA} / \mathrm{GO}$, melting and crystallization temperature of PCL were barely affected.

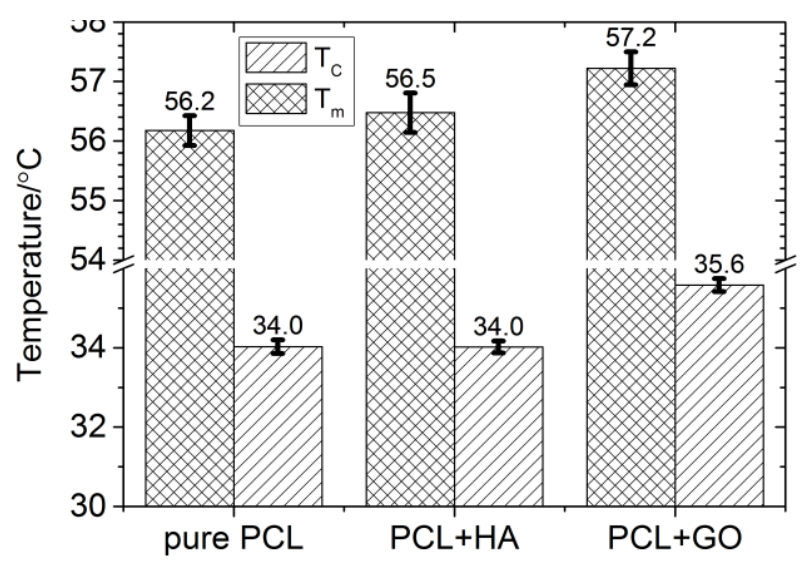

Figure 11 Crystallization $\left(\mathrm{T}_{\mathrm{c}}\right)$ and melting $\left(\mathrm{T}_{\mathrm{m}}\right)$ temperatures of three different samples.

$\mathrm{X}_{\mathrm{c}}$ was calculated using equation 3 , where $\Delta H_{f}\left(T_{m}\right)$ is the enthalpy of fusion measured at melting point; $\Delta H_{f}^{0}\left(T_{m}^{0}\right)$ is the enthalpy of fusion of completely crystalline PCL, which is around $139 \mathrm{~J} / \mathrm{g}$ 
(Oudhuis et al., 1994; Guo and Groeninckx, 2001; Jenkins and Harrison, 2006); w represents weight percentage of second phase inside PCL. The degree of crystallinity of each sample is displayed in Figure 12.

$$
X_{C}=\frac{\Delta H_{f}\left(T_{m}\right)}{(1-W) \Delta H_{f}^{0}\left(T_{m}^{0}\right)}
$$

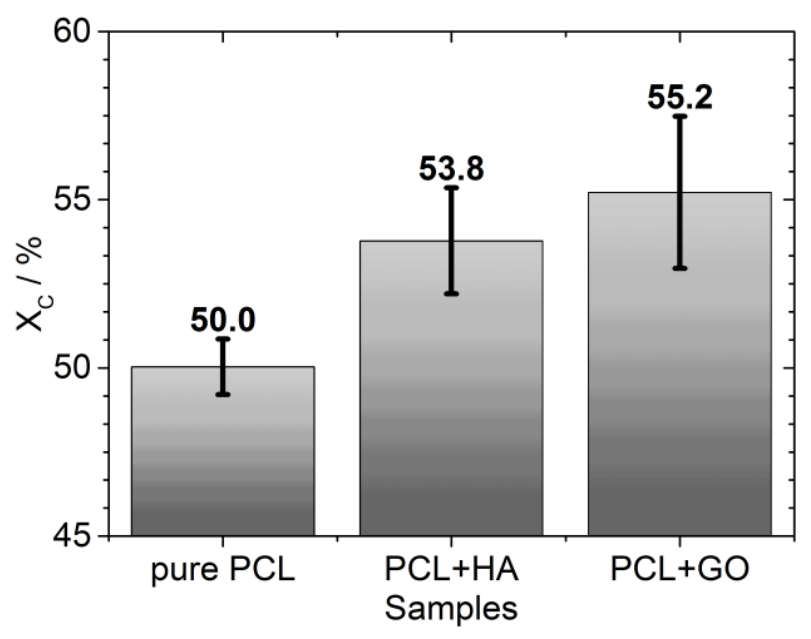

Figure 12 Degree of crystallinity $\left(\mathrm{X}_{\mathrm{c}}\right)$ of three different samples calculated from equation 3.

An 8\% increase in $\mathrm{X}_{\mathrm{c}}$ was observed when $20 \mathrm{wt}$ \% HA was included in PCL. It is believed that these nano particles served as nucleation sites for crystallization, encouraging heterogeneous nucleation of crystalline regions in PCL, thus a higher crystallinity was obtained. The effect of GO on PCL's $\mathrm{X}_{\mathrm{c}}$ was significantly stronger than that of HA, where $0.75 \mathrm{wt} \% \mathrm{GO}$ was responsible for a $10 \%$ increase in crystallinity.

\subsection{Correlation of thermal/mechanical properties}

PCL/HA exhibited better mechanical properties than pure PCL, specifically in terms of higher Young's modulus and yield strength. However, with the addition of 20 wt.\% HA, most of the thermal properties of the material were barely affected except for degree of crystallinity. A direct relationship between mechanical and thermal properties of PCL/HA was not found. Additionally, a small increment of crystallinity (8\%) was not able to justify such a great increase in Young's modulus (51\%) and yield strength (14\%). Amelioration in mechanical properties of PCL/HA mainly originated from strengthening effect of HA particles. Therefore, the material's system could be viewed as a polymer matrix composite (PMC), which mechanism have already been reported elsewhere in detail (Hao et al., 2002). 
PCL/GO also displayed improved mechanical behavior against pure PCL, however, according to statistical tests, only Young's modulus increased with the presence of GO nano particles. In terms of its thermal properties, most of them were just slightly influenced except for crystallinity. A significant increase $(10 \%)$ in $\mathrm{X}_{\mathrm{c}}$ was achieved even with an extremely low concentration of GO (0.75 wt.\%). The reinforcing effect of GO is originated by the increased degree of crystallinity. Rigid crystalline regions inside PCL are stiffer than amorphous ones as a result of oriented polymer chains, giving rise to higher overall modulus to the composite.

Inclusion of HA nano particles is able to improve mechanical properties of PCL, in particular for Young's modulus, which is in line with other research works (Hao et al., 2002; Baji et al., 2007; Idaszek et al., 2010).

In the literature, mechanical properties of PCL show significant improvements with the presence of GO even at very low content. For example it is reported that by incorporating $0.5 \mathrm{wt} . \% \mathrm{GO}$, the Young's modulus of PCL/GO rises from $209 \mathrm{MPa}$ to $311 \mathrm{MPa}$. However, this value decreases to $305 \mathrm{MPa}$ with the presence of 1 wt.\% GO (Wan and Chen, 2011). Wang et al also report a similar effect of GO, while Young's modulus of PCL/GO continues increasing when content of GO increases from $0.5 \mathrm{wt} . \%$ to $2 \mathrm{wt} . \%$. Improved mechanical properties are attributed to strengthening effects of GO particles, intrinsic properties of GO, strong interactions between GO particles and PCL matrix, as well as uniform distribution of GO (Wang et al., 2013). However, in the present work, by including 0.75 wt.\% GO, Young's modulus of PCL increased from $205 \mathrm{MPa}$ to $220 \mathrm{MPa}$ and that was considerably less than what have been reported in literature. In addition, other mechanical properties of the PCL/GO composite remained unaffected. Thus GO nano particles are highly likely to serve as nucleation sites that promote crystallization of PCL instead of reinforcing elements; in turn, it is the increased crystallinity that gives rise to an improved Young's modulus of the composite.

\section{Conclusions}

The first systematic study of 3D printed PCL/HA and PCL/GO filaments was conducted in this work. The filaments, which serve as building blocks for 3D bioactive scaffolds used in BTE were mechanically and thermally characterized. Thermal behaviours were analysed by DSC. It was found that most thermal properties of PCL/HA remained the same compared to pure PCL except for crystallinity, where an $8 \%$ increase was observed. Mechanical properties were obtained by tensile test and nano indentation. Compared with pure PCL, Young's modulus and indentation hardness of PCL/HA increased by $57 \%$ and $10 \%$, respectively. Improved mechanical properties result from the strengthening effect of HA particles, so PCL/HA could be viewed as a polymer matrix composite. Furthermore, the presence of HA increased yield strength but decreased yield strain of pure PCL by 
$14 \%$ and $22 \%$, respectively. Therefore it is concluded that nano HA particles make PCL less ductile, but stronger and significantly stiffer.

The presence of $0.75 \mathrm{wt}$.\% nano GO particles showed little influence on thermal properties of pure PCL except for degree of crystallinity, which increased from $50 \%$ to $55 \%$, corresponding to a $10 \%$ augment. Young's modulus of PCL/GO increased by 7\%, while other mechanical properties remained constant in comparison with pure PCL. Improved modulus is attributed to increased crystallinity instead of strengthening mechanism of GO particles. GO is more efficient at nucleating PCL and improving its Young's modulus than HA particles.

This work provides insights into the mechanism behind enhanced mechanical properties of PCLbased composites through a direct comparison between PCL/HA and PCL/GO. This will enable the design and production of 3D implants with improved mechanical performance for the regeneration of skeletal tissues. Additionally, an innovative clamping method in tensile test was developed. It could act as a guideline for testing fibrous materials when trying to avoid stress concentrations at the junction of specimen and mechanical grips. Further work involves testing filaments with different HA/GO loadings, followed by meshes and scaffolds. Optimised contents of HA and GO can be used to reduce risk of mechanical failures before and after in vivo implantation. Furthermore, PCL/GO scaffolds will be tested in vitro to investigate the influence of GO on the differentiation of human mesenchymal stem cells (hMSCs).

\section{Acknowledgements}

The authors would like to thank the funding awarded to Hanxiao Wang through the China Scholarship Council (CSC). Dr. Wei-Hung Chiang from the National University of Taipei is also acknowledged for the synthesis of GO. Appreciation is extended to Mr. Boyang Huang as well as Mr. Weiguang Wang from the school of Mechanical, Aerospace, and Civil Engineering, the University of Manchester for blend preparation and filament production.

\section{References}

Amini, A. R., Laurencin, C. T. and Nukavarapu, S. P. (2012), "Bone tissue engineering: recent advances and challenges", Critical Reviews in Biomedical Engineering, Vol. 40 No. 5, pp. 363-408.

Arafat, M. T., Gibson, I. and Li, X. (2014), "State of the art and future direction of additive manufactured scaffolds-based bone tissue engineering", Rapid Prototyping Journal, Vol. 20 No. 1, pp. 13-26.

Baji, A., Wong, S.-C., Liu, T., Li, T. and Srivatsan, T. S. (2007), "Morphological and x-ray diffraction studies of crystalline hydroxyapatite-reinforced polycaprolactone", Journal of Biomedical Materials Research Part B: Applied Biomaterials, Vol. 81B No. 2, pp. 343-50. 
Caetano, G., Violante, R., Ana, A. B. S., Murashima, A. B., Domingos, M., Gibson, A., Bártolo, P. and Frade, M. A. (2016), "Cellularized versus decellularized scaffolds for bone regeneration", Materials Letters, Vol. 182 pp. 318-22.

Dash, T. K. and Konkimalla, V. B. (2012), "Poly-e-caprolactone based formulations for drug delivery and tissue engineering: A review", Journal of Controlled Release, Vol. 158 pp. 15-33.

Domingos, M., Chiellini, F., Gloria, A., Ambrosio, L., Bartolo, P. and Chiellini., E. (2012), "Effect of process parameters on the morphological and mechanical properties of 3D Bioextruded poly $(\varepsilon-$ caprolactone) scaffolds", Rapid Prototyping Journal, Vol. 18 No. 1, pp. 56-67.

Domingos, M., Dinucci, D., Cometa, S., Alderighi, M., Bártolo, P. J. and Chiellini, F. (2009a), "Polycaprolactone scaffolds fabricated via bioextrusion for tissue engineering applications", International Journal of Biomaterials, Vol. 2009 p. (Article ID 239643).

Domingos, M., Intranuovo, F., Gloria, A., Gristina, R., Ambrosio, L., Bártolo, P. J. and Favia, P. (2013a), "Improved osteoblast cell affinity on plasma-modified 3-D extruded PCL scaffolds", Acta Biomaterialia, Vol. 9 pp. 5997-6005.

Domingos, M., Intranuovo, F., Russo, T., Santis, R. D., Gloria, A., Ambrosio, L., Ciurana, J. and Bartolo, P. (2013b), "The first systematic analysis of 3D rapid prototyped poly( $\varepsilon$-caprolactone) scaffolds manufactured through BioCell printing: the effect of pore size and geometry on compressive mechanical behaviour and in vitro hMSC viability", Biofabrication, Vol. 5 p. 13.

Domingos, M., Gloria, A., Coelho, J., Bartolo P. and Ciurana J. (2016), "Three-dimensional printed bone scaffolds: The role of nano/micro-hydroxyapatite particles on the adhesion and differentiation of human mesenchymal stem cells", Proceedings of the Institution of Mechanical Engineers, Part H: Journal of Engineering in Medicine p. 0954411916680236.

Eshraghi, S. and Das, S. (2010), "Mechanical and microstructural properties of Polycaprolactone scaffolds with 1-D, 2-D, and 3-D orthogonally oriented porous architectures produced by selective laser sintering", Acta Biomater, Vol. 6 No. 7, pp. 2467-76.

Estellés, J. M., Vidaurre, A., Dueñas, J. M. M. and Cortázar, I. C. (2008), "Physical characterization of polycaprolactone scaffolds", Journal of Materials Science: Materials in Medicine, Vol. 19 No. 1, pp. 189-95.

Fu, S., Ni, P., Wang, B., Chu, B., Peng, J., Zheng, L., Zhao, X., Luo, F., Wei, Y. and Qian, Z. (2012), "In vivo biocompatibility and osteogenesis of electrospun poly(epsilon-caprolactone)poly(ethylene glycol)-poly(epsilon-caprolactone)/nano-hydroxyapatite composite scaffold", Biomaterials, Vol. 33 No. 33, pp. 8363-71.

Guo, Q. and Groeninckx, G. (2001), "Crystallization kinetics poly(e-caprolactone) in miscible thermosetting polymer blends of epoxy resin and poly(E-caprolactone)", Polymer, Vol. 42 pp. 8647-55.

Hao, J., Yuan, M. and Deng, X. (2002), "Biodegradable and biocompatible nanocomposites of Poly( $\varepsilon$-caprolactone) with hydroxyapatite nanocrystals: thermal and mechanical Propertie", Journal of Applied Polymer Science, Vol. 86 pp. 676-83.

Hernlund, E., Svedbom, A., Ivergård, M., Compston, J., Cooper, C., Stenmark, J., McCloskey, E. V., Jönsson, B. and Kanis., J. A. (2013), "Osteoporosis in the european union: medical management, epidemiology and economic burden", Arch Osteoporos, Vol. 8 No. 136, pp. 1-115. 
Huang, X., Yin, Z., Wu, S., Qi, X., He, Q., Zhang, Q., Yan, Q., Boey, F. and Zhang, H. (2011), "Graphene-based materials: synthesis, characterization, properties, and applications", Small, Vol. 7 No. 14, pp. 1876-902.

Hyung, K. G. and Seong, K. M. (2014), "Highly porous electrospun 3D polycaprolactone/ $\beta$-TCP biocomposites for tissue regeneration", Materials Letters, Vol. 120 pp. 246-50.

Idaszek, J., Bruinink, A., Święszkowski, W. and Kurzydłowski, K. J. (2010), "Biodegradable ternary nanocomposites with improved mechanical properties", European Cells and Materials, Vol. 28 p. 118.

Jenkins, M. J. and Harrison, K. L. (2006), "The effect of molecular weight on the crystallization kinetics of polycaprolactone", Polymers For Advanced Technologies, Vol. 17 pp. 474-8.

Kai, W., Hirota, Y., Hua, L. and Inoue, Y. (2008), "Thermal and mechanical properties of a poly( $\varepsilon$ caprolactone)/graphite oxide composite", Journal of Applied Polymer Science, Vol. 107 pp. 1395400 .

Lee, S.K., Kim, H. and Shim, B.S. (2013), "Graphene: an emerging material for biological tissue engineering", Carbon Letters, Vol. 14 No. 2, pp. 63-75.

Lohfeld, S., Cahill, S., Barron, V., McHugh, P., Dürselen, L., Kreja, L., Bausewein, C. and Ignatius, A. (2012), "Fabrication, mechanical and in vivo performance of polycaprolactone/tricalcium phosphate composite scaffolds.", Acta Biomaterialia, Vol. 8 No. 9, pp. 3446-56.

Nor, F. M., Lee, H. Y., Lim, J. Y. and Kurniawan, D. (2016), "Strain rate and temperature effects on elastic properties of polycaprolactone/starch composite", e-Polymers, Vol. 16 No. 3, pp. 217-23.

O’Brien, F. J. (2011), "Biomaterials and scaffolds for tissue engineering", MaterialsToday, Vol. 14 No. 3, pp. 88-95.

Oliver, W. C. and Pharr, G. M. (2004), "Measurement of hardness and elastic modulus by instrumented indentation: Advances in understanding and refinements to methodology", Journal of Materials Research, Vol. 19 No. 1, pp. 3-20.

Oudhuis, A. A. C. M., Thiewes, H. J., Hutten, P. F. v. and Brinke, G. t. (1994), "A comparison between the morphology of semicrystalline polymer blends of poly( $\varepsilon$-caprolactone)/poly(vinyl methyl ether) and poly(e-caprolactone)/(styrene-acrylonitrile)", Polymer, Vol. 35 No. 18, pp. 393642.

Patricio, T., Domingos, M., Gloria, A., D’Amora, U., Coelho, J. F. and Bártolo, P. J. (2014), "Fabrication and characterisation of PCL and PCL/PLA scaffolds for tissue engineering", Rapid Prototyping Journal, Vol. 20 No. 2, pp. 145-56.

Salehi, S., Bahners, T., Gutmann, J. S., Gao, S.-L., Mader, E. and Fuchsluger, T. A. (2014), "Characterization of structural, mechanical and nano-mechanical properties of electrospun PGS/PCL fibers.", RSC Advances, Vol. 4 pp. 16951-7.

Sayyar, S., Murray, E., Thompson, B. C., Gambhir, S., cer, D. L. O. and Wallace, G. G. (2013), "Covalently linked graphene/polycaprolactone composites engineering", Carbon, Vol. 52 pp. 296304. 
Suchanek, W. and Yoshimura, M. (1998), "Processing and properties of hydroxyapatite-based biomaterials for use as hard tissue replacement implants", Journal of Materials Research, Vol. 13 No. 1, pp. 94-117.

Tan, E. P. S., Ng, S. Y. and Lim, C. T. (2005), "Tensile testing of a single ultrafine polymeric fiber", Biomaterials, Vol. 26 pp. 1453-6.

Wan, C. and Chen, B. (2011), "Poly( $\varepsilon$-caprolactone)/graphene oxide biocomposites: mechanical properties and bioactivity", Biomedical Materials, Vol. 6 No. 5, pp. 55010-7.

Wang, G.-s., Wei, Z.-y., Sang, L., Chen, G.-y., Zhang, W.-X., Dong, X.-f. and Qi, M. (2013), "Morphology, crystallization and mechanical properties of poly( $\varepsilon$-caprolactone $) /$ graphene oxide nanocomposites", Chinese Journal of Polymer Science, Vol. 31 No. 8, pp. 1148-60.

Wang, W., Caetano, G. F., Chiang, W.-H., Braz, A. L. c., Blaker, J. J., Frade, M. A. C. and Bártolo, P. J. (2016), "Morphological, mechanical and biological assessment of PCL/pristine graphene scaffolds for bone regeneration", International Journal of Bioprinting, Vol. 2 No. 2, pp. 95-104.

Williams, J. M., Adewunmi, A., Schek, R. M., Flanagan, C. L., Krebsbach, P. H., Feinberg, S. E., Hollister, S. J. and Das, S. (2005), "Bone tissue engineering using polycaprolactone scaffolds fabricated via selective laser sintering", Biomaterials, Vol. 26 pp. 4817-27.

Zhao, H., Zhao, G., Turng, L.-S. and Peng, X. (2015), "Structural evolution of uniaxial tensiledeformed injection molded Poly( $\varepsilon$-caprolactone)/hydroxyapatite composites", Polymer Composites, doi: $10.1002 / p c .23747$. 